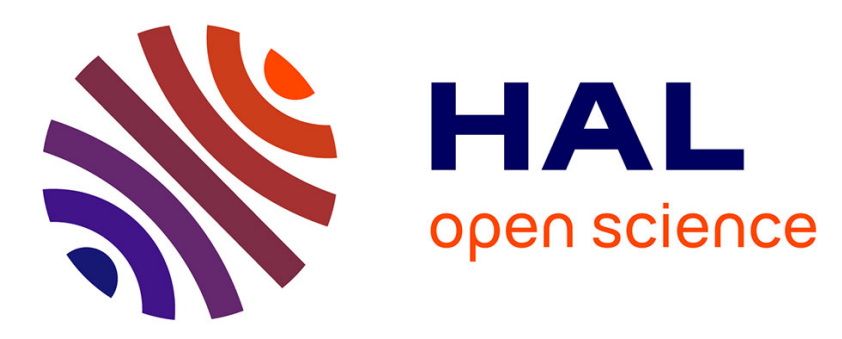

\title{
Will naturally ventilated dwellings remain safe during heatwaves?
}

\author{
Jean-Marie Alessandrini, Jacques Ribéron, David da Silva
}

\section{To cite this version:}

Jean-Marie Alessandrini, Jacques Ribéron, David da Silva. Will naturally ventilated dwellings remain safe during heatwaves?. Energy and Buildings, 2019, 183, pp.408 - 417. 10.1016/j.enbuild.2018.10.033 . hal-02309808

\section{HAL Id: hal-02309808 \\ https://hal-cstb.archives-ouvertes.fr/hal-02309808}

Submitted on 9 Oct 2019

HAL is a multi-disciplinary open access archive for the deposit and dissemination of scientific research documents, whether they are published or not. The documents may come from teaching and research institutions in France or abroad, or from public or private research centers.
L'archive ouverte pluridisciplinaire HAL, est destinée au dépôt et à la diffusion de documents scientifiques de niveau recherche, publiés ou non, émanant des établissements d'enseignement et de recherche français ou étrangers, des laboratoires publics ou privés. 


\title{
Will naturally ventilated dwellings remain safe during heatwaves?
}

\author{
Jean-Marie Alessandrini*1 $^{1}$, Jacques Ribéron², David Da Silva ${ }^{1}$ \\ 1 Energy \& Environment Department \\ Centre Scientifique et Technique du Bâtiment (CSTB) \\ 84 avenue Jean-Jaurès, Champs-sur-Marne, \\ 77447 Marne-la-Vallée cedex 2, France \\ Corresponding author: \\ jean-marie.alessandrini@cstb.fr
}

\begin{abstract}
Heatwaves are responsible for many deaths due to hot weather. Natural ventilation is promoted as a cooling solution to reduce the impacts of climate change because of its energy-saving potential.

This paper addresses the prediction of heat-related health risk situations in naturally ventilated dwellings, where indoor thermal conditions depend on external climate and occupant behaviour. Thus, the operating limits of a dwelling vary according to its dynamic thermal response to indoor and outdoor stresses.

To secure a building design, a method to improve the prediction of heat-related health risks is proposed that links predicted percentage dissatisfied (PPD) and wet-bulb globe temperature (WBGT) indicators to distinguish a moderately warm situation from a heat stress situation (WBGT $\left.>29^{\circ} \mathrm{C}\right)$. Simulations are performed for a dwelling during the 2015 heatwave in Paris (France) to test the method.

In the example, natural ventilation was found to reduce the indoor temperature, but there remains ambiguity regarding the ability of natural ventilation to provide moderate conditions. According to the scope of the ergonomic standards, "moderate thermal environment" and "heat stress" temperature ranges are not contiguous. Bridging of this gap requires establishing thermal comfort ranges and heat stress thresholds adapted to people according to their acclimatisation level and their sensitivity to heat.
\end{abstract}

\section{DECLARATIONS OF INTEREST}

None

\section{KEYWORDS}

Thermal comfort, heat stress, natural ventilative cooling, health, climate change 


\section{INTRODUCTION}

A well-established relationship exists between extremely high temperatures and human morbidity and mortality [1] [2]. Heatwaves represent a real risk to vulnerable populations such as the unacclimated, elderly, and sick as well as infants. The main predisposing factors for heat-related illness are given in a World Health Organisation (WHO) report [2]. The 2003 heatwave in Europe killed approximately 70000 people [3] and caused 14800 excess deaths in France [4]. This heatwave led the French Minister of Health to introduce a National Heatwave Plan (NHP) in 2004. The NHP defines actions aimed at preventing health impacts during episodes of extreme heat. The NHP includes a Heat Health Watch Warning System (HHWWS) [5]. The 2006 heatwave in France suggested that the NHP measures had been effective, with 4400 fewer deaths than anticipated [6]. Therefore, French people are now better prepared to handle significant heatwaves than they were previously. The 2006 heatwave in France caused 2000 excess deaths in an 18-day period, while the 2015 heatwave caused 3300 excess deaths in a 26-day period. Despite the prevention measures, the impacts of heatwaves remain significant and demand continued research.

According to the literature, five types of heat-related risk factors can be considered: environmental factors (e.g., lack of vegetation, urban heat island, urban density, pollution, air humidity, occupational heat-exposure, building construction quality), socio-demographic factors (e.g., age, gender, heat acclimatisation level, and specific populations such as disabled persons, the elderly, infants, pregnant women, workers, and athletes), health factors (e.g., obesity, pre-existing diseases, and drug intake), social factors (e.g., poverty and social isolation), and behavioural factors (e.g., inadequate clothing, reduced mobility, and consumption of caffeinated or alcoholic beverages) [2] [3] [7]. Following the 2003 heatwave, a case study showed that the risk factor increased 4-fold for people who lived on the top floor of an uninsulated block of flats [8]. Other factors, such as the number of windows and the inability to create draughts by cross-ventilation were associated with increased death rates [9].

The effects of heat are worsened by the urban heat island effect, which results from the increased heat retention of buildings and paved surfaces compared with transpiration, shading, and air flow promotion by vegetation. Today, one quarter of the French population is over the age of 60, and three quarters of the population live in urban areas. In the coming decades, the ageing and urban populations will increase, leading to an increased risk of heat-related deaths. Long-duration heatwaves and prevailing warm annual conditions are becoming increasingly likely because of the warming of the planet. Significant increases in extreme heat risks are projected under all climate change scenarios.

The previous review outlines the great challenges associated with climate change, and because air conditioning is an effective way for people to protect themselves from heat-related effects, the sales of these systems are impacted 
by the "fear of heat waves" [10]. Approximately 5\% of French dwellings are equipped with mechanical cooling systems [11]. Thus, the potential for the popularity of air conditioning to increase is high, which would lead to increased energy consumption and $\mathrm{CO}_{2}$-related emissions. Indeed, M. Santamouris estimated that the current cooling energy consumption of $0.7 \mathrm{PWh} /$ year from residential buildings throughout the world will increase to a value between 1.7 and $11.8 \mathrm{PWh} /$ year by 2050 . The significant variation is deeply linked to the large uncertainty of the future dissemination of air conditioners in dwellings [12]. Thus, limiting the distribution of air conditioners is a great challenge, and natural ventilation may be a solution.

A naturally ventilated school [13] was presented ${ }^{1}$ as an example of a building adapted to climate change. A supplement to the CEN Guide 32 [14] regarding climate change adaptation standards recommended the following: "give[s] preference to equipment that is not weather sensitive". A contrast exists between these two comments, and which of these guidelines designers should follow remains unclear. Cautiously, the CEN Guide 32 [14] recommends the following: "ensure buildings can [...] provide thermal comfort in a changing climate". However, whether natural ventilation would be reliable enough to prevent thermal stress and the associated dire consequences is not discussed. The operating limits of natural ventilation need to be determined to evaluate whether natural ventilation is a safe alternative solution. Thermal comfort is a daily requirement, whereas heat stress avoidance is only required only at rare events. The link between both requirements can be established with the frequency of climate events. Figure 1 is based on an IPCC report [15] and explains this link in the context of climate change.

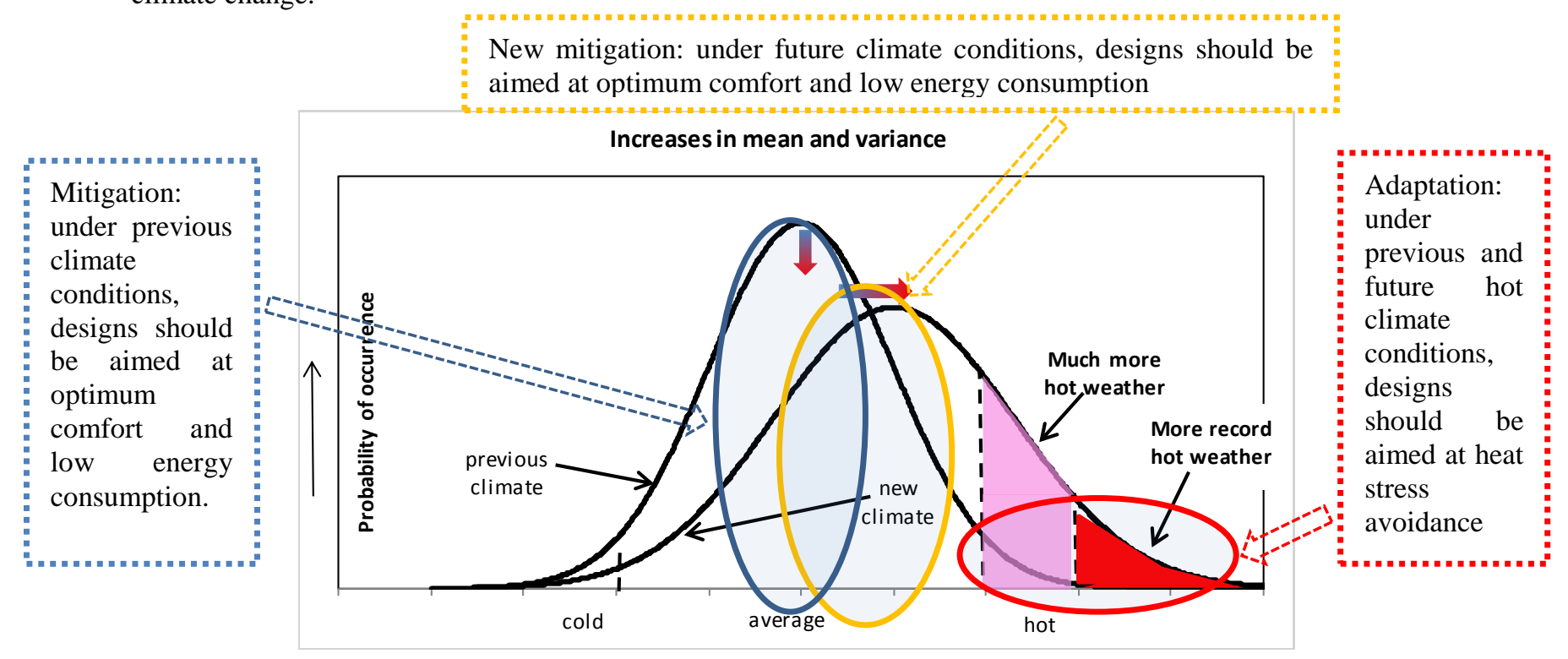

Figure 1: Schematic depiction of the effects on extreme temperatures when both the mean and variance increase for a normal temperature distribution based on an IPCC report [15]

${ }^{1} 11^{\text {th }}$ International Weather and Climate Forum, April 2014. 
Figure 1 represents a probability distribution of current daily outside temperatures, i.e., the previous climate, and a projection of the future climate, i.e., the new climate. This theoretical climate projection shows a spread of the distribution with a shift toward increasingly warm daily temperatures. A first estimation of the median temperature is given for the Paris area. Probability densities were calculated with data provided by Aladin, the regional climate model of Météo-France [16], for two thirty-year periods, from 1971 to 1990 for the previous climate and from 2041 to 2070 for the new climate, under the highly pessimistic RCP 8.5 scenario [17]. For summer, the daily median temperature is $17.5^{\circ} \mathrm{C}$ for the previous climate and $20.7^{\circ} \mathrm{C}$ for the new climate with probability densities of 13 and 8 , respectively.

At the end of the distribution, in the red and pink areas, the probability densities of the temperatures increase under the new climate. Because the energy system is not sized according to extreme and rare events, the lowest temperatures limiting the pink area for the previous climate and the red area for the new climate can be considered the sizing points for a cooling system. Therefore, these sizing points can be quantified using the ISO 15927-2 standard [18], which recommends that the threshold be established at a value whose probability of being exceeded is less than $1 \%$. When calculated at the $99^{\text {th }}$ percentile for the previous example of the Paris area, the sizing thresholds are $26.1^{\circ} \mathrm{C}$ and $30.8^{\circ} \mathrm{C}$ for the previous and new climates, respectively. These figures for Paris lead to a distribution close to the theoretical distribution proposed in Figure 1.

For air-conditioned dwellings, the sizing point requirement is to provide thermal comfort, but for hot climate events, such a requirement is not defined. However, with climate-dependent passive systems, a prolonged moderately warm period might also cause indoor thermal stress and a possible increase in heat-related morbidity. Thus, for these technical solutions, especially for naturally ventilated dwellings, the border is porous between the sizing point and the risk range, and the requirements must be defined. The design is then difficult to achieve, as the weather requirements to study thermal stress cannot be selected only through climate analysis.

The long-term goal is to help professionals design naturally ventilated buildings adapted to climate change so that their potential to avoid heat-related health risks during both present and future heatwaves is known. Therefore, establishment of the running limits is essential. The aim of the paper is to develop a method at the design stage to examine the indoor thermal environments of these non-air-conditioned dwellings, which are popular in France, during a heat stress period in a changing climate.

In this paper, an overall view of the method is introduced. The principles of the method, which are based on different requirements according to thermal comfort or heat stress, are explained. For professional use, indices for thermal comfort and heat-related health risks are provided by international standards ISO 7730 [19], and ISO 7243 [20], and the numerical models that are used are also strongly linked to the standards ISO 13790 [21] and EN 
15242 [22]. The method is tested using the example of a typical dwelling in France to confirm its functionality and to define the limits of standards. First, the results are presented and compared to different thresholds relative to heat stress depending on human physiological limits and on levels of acclimatisation.

\section{METHOD}

First, the principle of the method for interpreting the results regarding mitigation and adaptation to climate change is presented. Then, the method is described step by step. Finally, the example used to test the method is introduced.

\subsection{Method principle}

Thermal comfort requirements and heat-related health requirements must be distinguished. In reference to the automotive segment, after a crash test, occupants are expected to be safe. On the same theory, under a heat stress test, the dwelling should protect people from health hazards, whereas in the most frequent periods, thermal comfort is required. Thus, the intended indoor thermal conditions are not the same under extreme and common weather conditions. Figure 2 presents increasing health risks versus increasing discomfort. A safe indoor environment is on the left, and an unsafe environment is on the right. The blue arrows show the method proposed to design a building to save energy and ensure occupant health.

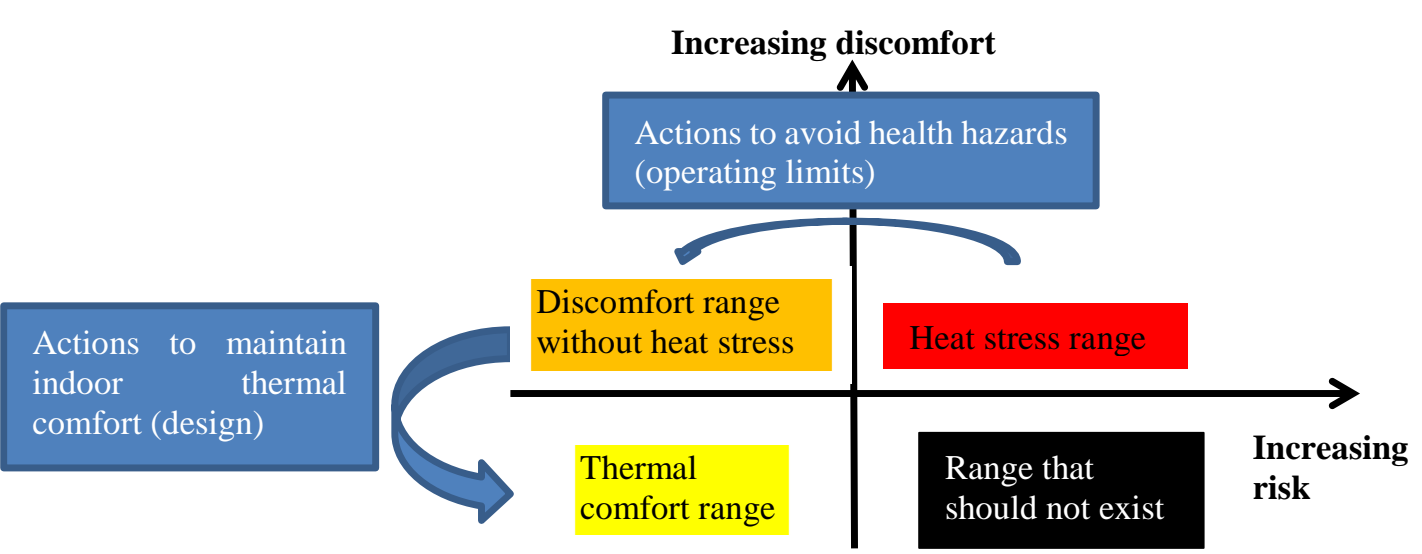

Figure 2: Relationship between thermal comfort and health risk

Solutions that guarantee comfort under usual circumstances-from the top left to the bottom left-should also protect the occupants from health hazards under extreme events-from the top right to the top left. However, an indoor environment characterized by one index as comfortable and another as thermally stressful should be avoided. Such an environment is represented by the black box in Figure 2. The intersection at the boundary between thermal comfort and heat stress is needed to apply the method.

\subsection{Main steps of the method}

The primary steps of the method are introduced in Figure 3. According to the long-term goal, the tools available for building design are mainly standards related to: 
- the hygrothermal performance of buildings to select climate data and to calculate the internal temperatures of a room and

- the ergonomics of the thermal environment for comfort and heat stress.

\section{Description of the case study:}

- Weather data (hot weather and (IBM) biometeorological indices)

- Building (size, aspect, and physical characteristics of the envelope, ...)

- Occupants (activity, clothing, and behaviour, especially window-opening strategy)

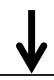

\section{Calculation of indoor conditions:}

- Simulation software for dynamic thermal and air flow rates for building energy performance design

- Physical parameters (temperatures: air, operative, and mean radiant; and relative humidity)

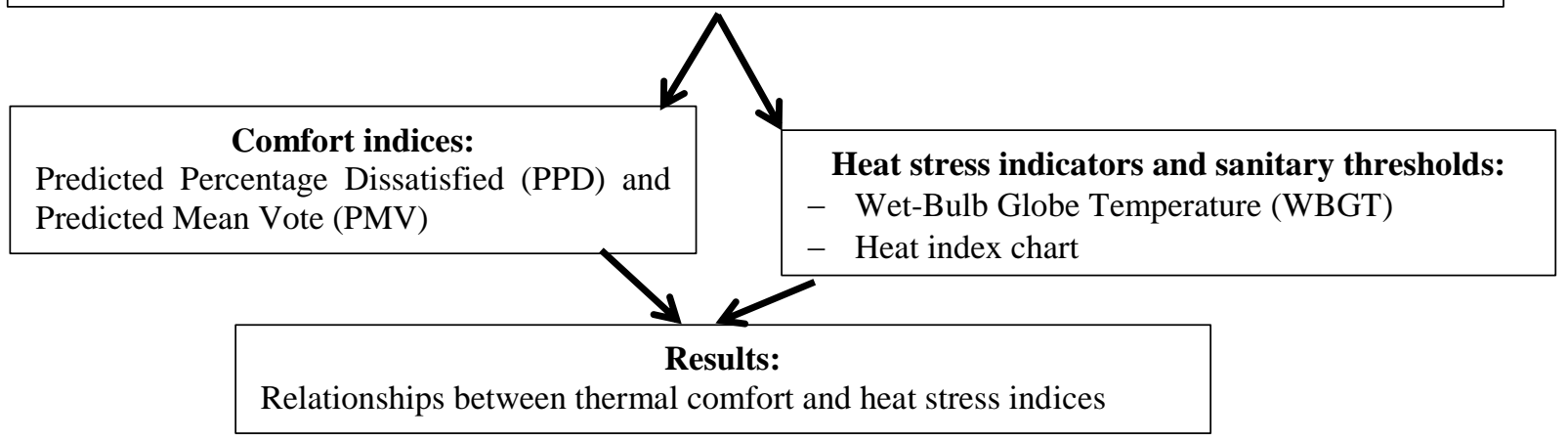

Figure 3: Chronological sequence of the basic steps of the method

\subsection{Biometeorological indicators}

For a passive building, the weather selection for a risk analysis cannot be limited to a climate analysis as the health impact is also needed. The HHWWS classifies NHP actions into four levels:

- Seasonal vigilance, continuously activated from $1^{\text {st }}$ of June to $30^{\text {th }}$ of September,

- Warning level, when the thresholds are to be reached within three days. Preparation for staggered implementation of the preventive measures detailed in the NHP,

- Heatwave alert, when the thresholds are reached. Implementation of the appropriate sanitary and social measures,

- Maximum mobilization level, when the thresholds are reached and the heatwave tends to last or when exceptional conditions are met.

The HHWWS was developed on the basis of a retrospective analysis of mortality and meteorological data from fourteen pilot cities representative of the different climates of mainland France [5]. Several heatwave indicators were tested in relation to the levels of excess mortality. An indicator that mixes minimum and maximum temperatures was chosen. Excess mortality levels were set at $50 \%$ for Paris, Lyon, Lille and Marseille and $100 \%$ for the other smaller cities. The biometeorological indicator (IBM) is, therefore, the combination of the paired minimum and maximum biometeorological indices (IBMin and IBMax, respectively), where IBMin is the sliding 
mean over three days of minimum temperatures, and IBMax is the sliding mean over three days of maximum temperatures. The HHWWS is regularly assessed and updated annually [23].

\subsection{Occupant behaviours}

An indoor thermal environment is strongly impacted by the occupants. Metabolic water vapour and heat production depend on activity levels. Moreover, window opening strategy, solar shading practice and appliance use are deeply linked to occupant behaviours. Thus, building occupation is needed to predict indoor temperature and humidity. Behaviour scenarios are more reliable when done in cooperation with building project stakeholders. In this paper, the given scenarios for the example are introduced in section 2.7 .

\subsection{Thermal and air flow rate models}

Indoor environmental conditions are calculated with a dynamic thermal model linked with a mass air flow balance model that includes large opening windows and is called COMETh [24]. This integrated model has been used by French thermal regulations since 2000 [25], first for summer thermal comfort, then for heating, cooling, ventilation, sanitary hot water and lighting consumptions. COMETh is acquainted with thermal design engineers at a national scale and can calculate indoor environment conditions for different occupant behaviours and under different climates.

Thermal balance is computed with a 5RC equivalent electric representation of the building components, which is similar to the ISO 13790 [21] simplified model but has been slightly modified to improve the calculation of freerunning indoor temperatures. This calculation has been successfully compared to the ASHRAE 140 standard [26], including cases with hourly free float temperatures [27]. The operative temperature, Top $\left({ }^{\circ} \mathrm{C}\right)$, is calculated at each hourly time step with air $\left(\mathrm{T}_{\mathrm{a}}\left({ }^{\circ} \mathrm{C}\right)\right)$ and mean radiant $\left(\mathrm{T}_{\mathrm{rm}}\left({ }^{\circ} \mathrm{C}\right)\right)$ temperatures and assuming that convective and radiant transfers around the body have the same magnitude.

$$
\mathrm{Top}=\frac{T_{a}+T_{r m}}{2}
$$

$\mathrm{T}_{\mathrm{rm}}$ is obtained using the Walton radiation model [28]. Solar radiation flux is distributed on walls according to the thermal dynamic behaviour of the walls within an hour. Two types of walls are considered according to their hourly periodic penetration depth of a thermal wave, which is calculated based on ISO 13786 [29]:

- thick walls, in which the thickness is larger than its hourly penetration depth, are in a transitory state,

- thin walls, in which the thickness is smaller than its hourly penetration depth, are in a steady state.

However, for each thick wall, the layer between the inner surface and the hourly penetration depth is in a steady state. Thus, this layer is also considered a thin wall.

The daily thermal capacity of the walls is calculated according to ISO 13786 [29] and linked to the temperature node of thick walls. All thin walls and thin layers of thick walls are gathered in an equivalent thin wall, with a 
node temperature linked to the air temperature node. The radiation flux absorbed by the temperature node of the equivalent thin wall corresponds to the ratio between the hourly and daily thermal capacities. The hourly thermal capacity of the equivalent thin wall is the sum of the hourly capacities of each thin walls or layers of thick walls calculated using ISO 13786 [29].

The air change rate is calculated according to the De Gids and Phaff air flow model through large openings [30]. This model has been used for the IEA Annex 20 research, especially in single-sided ventilation studies [31], and is selected here because it is used in the European standard that addresses calculation methods for the determination of air flow rates in buildings, namely, EN 15242 [22]. This model also presents a good balance between the limited amount of input data available at the design stage and the model accuracy according to Larsen [32]. Moreover, the model provides a general expression of the ventilation rate $\mathrm{Q}\left(\mathrm{m}^{3} / \mathrm{s}\right)$ through an open window as a function of $\Delta \mathrm{T}$ $(\mathrm{K})$, the indoor-outdoor temperature difference $\mathrm{U}_{\text {wind, }}$, the wind velocity $(\mathrm{m} / \mathrm{s})$, and fluctuating terms:

$$
Q=\frac{A}{2} \times \sqrt{C_{1} U_{\text {wind }}^{2}+C_{2} H \Delta T+C_{3}}
$$

where $A\left(\mathrm{~m}^{2}\right)$ is the area of the window opening; $\mathrm{H}(\mathrm{m})$ is the height of the opening; $\mathrm{C}_{1}$ is a dimensionless wind coefficient equal to $0.001 ; \mathrm{C}_{2}$ is the buoyancy constant equal to 0.0035 ; and $\mathrm{C}_{3}$ is the turbulence constant equal to 0.01 .

For humidity balance, the incoming and outgoing dry air flow rates are supposed to be equal. Without cooling systems, the variation in absolute humidity is given by equation (3).

$$
\frac{d w_{\text {ex }}}{d t}=\frac{\sum Q_{\text {in }}\left(w_{\text {in }}-w_{\text {ex }}\right)+\text { internal Latent loads }}{V \rho_{\text {indoor }}}
$$

$\mathrm{Q}_{\text {in }}$ is the incoming air flow rate $(\mathrm{kg} / \mathrm{s}) ; \mathrm{W}_{\text {in }}(\mathrm{kg} / \mathrm{kg})$ is the absolute humidity of the incoming air; $\mathrm{w}_{\mathrm{ex}}(\mathrm{kg} / \mathrm{kg})$ is the absolute humidity exhausting from the dwelling; internal latent loads $(\mathrm{kg} / \mathrm{s}) ; \mathrm{V}$ is the dwelling volume $\left(\mathrm{m}^{3}\right)$; and $\rho_{\text {indoor }}\left(\mathrm{kg} / \mathrm{m}^{3}\right)$ is the indoor air density. $\mathrm{w}_{\mathrm{ex}}$ is assumed to be equal to the absolute humidity within the dwelling. The Cranck Nicholson method is used to link the thermal and air flow models. The time step result is the average between the end and beginning time step solutions. The solution at the end of the previous time step is assigned to the beginning of the next time step. Thus, the beginning temperature value is used to calculate the air flow rate through windows and the humidity balance at the end time step.

The models assume that the indoor temperature and humidity are spatially homogeneous, and each wall has isothermal surfaces. The radiation balance is calculated for a cube with the same absorption and emissivity for all walls. To linearize the radiation equation, the inside wall temperatures must be similar. According to these assumptions, only an overall thermal feeling can be assessed, while the effects of draught, vertical air temperature differences or radiant asymmetry are not evaluated. 


\subsection{Thermal comfort and thermal stress indices}

Indices and their thresholds have to be selected to find the boundary between the thermal comfort area and heat stress. Therefore, a literature review was conducted.

Goromosov [33] carried out studies in apartments in hot climates (outdoor temperatures ranging from $35^{\circ} \mathrm{C}$ to $38^{\circ} \mathrm{C}$ ). The outcomes suggest that people feel "comfortable" at an indoor temperature of $25^{\circ} \mathrm{C}$, which is associated with a heart rate $(\mathrm{HR})$ of 65 beats $/ \mathrm{min}$. People feel "warm" at $27^{\circ} \mathrm{C}(\mathrm{HR}=68$ beats $/ \mathrm{min})$, "hot" at $31^{\circ} \mathrm{C}(\mathrm{HR}=72$ beats/min) and "hot and oppressive" at $34^{\circ} \mathrm{C}(\mathrm{HR}=74$ beats $/ \mathrm{min})$.

Weihe reviewed the health impacts of adverse thermal conditions [34]. A range from $17^{\circ} \mathrm{C}$ to $31^{\circ} \mathrm{C}$ was defined as an acceptable range for thermal comfort neutrality without health impacts. Then, the symptoms of discomfort and health risks are listed, and they include fatigue, lack of appetite, and hyperthermia at temperatures higher than $31^{\circ} \mathrm{C}$, while the health effects are heat stroke and heart failure at temperatures significantly higher than $31^{\circ} \mathrm{C}[34]$ $[35]$.

The Heat Index Chart (HIC) developed by the US National Oceanographic and Atmospheric Administration [36] provides, according to the temperature and humidity, physiological disorders in cases of prolonged exposure to heat. The health effects are classified in four levels: caution level (fatigue), extreme caution level (muscle cramps, physical exhaustion), danger level (heatstroke possible), extreme danger level (high risk of heat stroke). For sedentary activity (circa $1.2 \mathrm{met}$ ) and light clothing (circa 0.6 clo), the thermal comfort indices show that the comfort requirements are met as far as the Top does not exceed circa $26^{\circ} \mathrm{C}$.

The standards are accepted in France as supporting good design practices, and standard ISO 7730 [19] is used. This standard addresses the analytical determination and interpretation of thermal comfort using calculation of the PMV and PPD indices, and its scope is limited to moderate thermal environments, i.e., an air temperature below $30^{\circ} \mathrm{C}$.

Those thresholds are mainly air or operative temperatures in a homogeneous environment. For the HIC index, the temperature is given with humidity assumptions, which are marked on the same temperature scale from thermal comfort to heat stress thresholds (Figure 4).

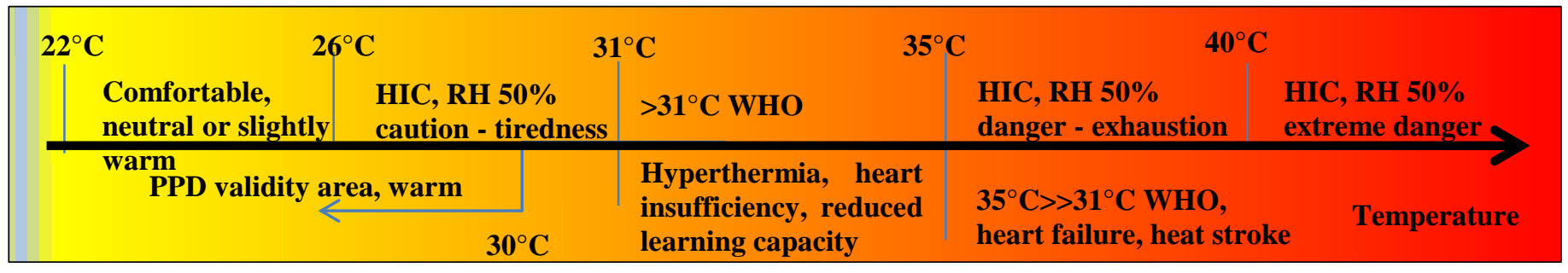

Figure 4: Comfort and health continuum in warm and hot temperatures 
The PPD was built with original data collected in a climate chamber [37]. The experimental device is therefore different from a room with a free-floating temperature, which may modify the interpretation of thermal comfort. The standard EN 15251 [38] provides in its informative annex an adaptive thermal comfort approach for rooms without air conditioning. According to this approach, thermal comfort limits are provided by an indoor temperature threshold that depends on the outside temperatures on the previous day. The upper limit of the acceptable indoor temperature in calm air is $32.7^{\circ} \mathrm{C}$, and it can rise to $34^{\circ} \mathrm{C}$ with a $0.5 \mathrm{~m} / \mathrm{s}$ air velocity. These thresholds are greater than the temperature recommended by the World Health Organization (WHO). Thus, to secure the design, thresholds proposed by adaptive comfort are not used.

A set of standards is available for continuous assessment of the thermal environment from thermal comfort to heat stress. ISO 15265 standard [39] addresses the risk assessment strategy for the prevention of stress or discomfort and recommends using ergonomic indices measured or calculated depending on whether the building is in the operating or design stage. The recommendations of this standard are used when possible.

Indeed, the thermal comfort and heat stress indices must fit together and be compatible with the physical models used to calculate the indoor thermal environment. The choice of indicators is therefore dependent on the thermal model, which requires inputs, including occupant behaviour and activity and their associated metabolic heat loads, the opening of windows and use of solar protection, and assumptions regarding clothing insulation levels. The spatial and temporal scales of the indicators must be mutually consistent and consistent with the thermal model hourly time step and the spatial homogeneity of the indoor thermal environment.

These criteria and ISO 11399 [40] are then used to select two main standards with adjacent scopes:

- $\quad$ ISO 7730 [19] for a moderate thermal environment with a Predicted Mean Vote (PMV),

- $\quad$ ISO 7243 [20] for a hot thermal environment with a Wet-Bulb Globe Temperature (WBGT).

Both indices are consistent with an hourly time step and are calculated to express thermal comfort or heat stress for the body as a whole in a homogeneous indoor environment during the time step. The thresholds of the indices depend on assumptions relative to occupant behaviours, which are used to calculate the indoor thermal environment.

The Predicted Percentage Dissatisfied (PPD) can be obtained from the PMV. In this study, $\mathrm{T}_{\mathrm{a}}, \mathrm{T}_{\mathrm{rm}}$ and relative humidity $(\mathrm{RH})$ are calculated by the model, while indoor air velocity $\left(\mathrm{V}_{\mathrm{a}}\right)$, metabolic rate (Met), and clothing insulation (Clo) are given data. However, $\mathrm{V}_{\mathrm{a}}$ is not calculated using the thermal model. To evaluate thermal comfort, two air velocities are used to calculate the PPD, one low $(0.1 \mathrm{~m} / \mathrm{s})$, representative of still air, and the other high $(0.4 \mathrm{~m} / \mathrm{s})$, representative of an air flow pattern that is limited to avoid annoying draughts [41]. 
The WBGT index is a weighted sum of the natural wet-bulb temperature, $\mathrm{t}_{\mathrm{nw}}\left({ }^{\circ} \mathrm{C}\right)$ and globe temperature, $\mathrm{t}_{\mathrm{g}}\left({ }^{\circ} \mathrm{C}\right)$. For indoor conditions, the WBGT formula without sun loads is used:

$$
\text { WBGT }=0.7 \mathrm{t}_{\mathrm{nw}}+0.3 \mathrm{tg}_{\mathrm{g}}
$$

The WBGT is to be measured. Thus, ISO 7726 [42] is used to establish the link with the thermal model. $\mathrm{t}_{\mathrm{g}}$ can be assumed to be equal to the Top calculated with the model. To obtain $t_{n w}$, the natural wet-bulb temperature from the Malchaire formula [43] is used:

$$
\left(t_{n w}-t_{w b}\right)=\frac{0.16\left(t_{g}-t_{a}\right)+0.8}{200}\left(560-2 R H-5 t_{a}\right)-0.8
$$

All temperatures are in ${ }^{\circ} \mathrm{C}$, and $\mathrm{RH}$ is in percent. All parameters are calculated by the model except $\mathrm{t}_{\mathrm{wb}}$, which is the psychrometric wet-bulb temperature. According to psychrometric chart, $\mathrm{t}_{\mathrm{wb}}$ is the cross-section of a continuous enthalpy curve and an air saturation curve. Enthalpy is calculated with $\mathrm{t}_{\mathrm{a}}$ and $\mathrm{RH}$, as given by the model. However, Malchaire [43] specifies that good accuracy is obtained for $V_{a}$ values below $0.15 \mathrm{~m} / \mathrm{s}$. For an air velocity higher than $0.15 \mathrm{~m} / \mathrm{s}$, the $\mathrm{t}_{\mathrm{nw}}$ is lower than the natural wet-bulb temperature calculated with formula (5) and higher than $\mathrm{t}_{\mathrm{wb}}$. Thus, for air velocities greater than $0.15 \mathrm{~m} / \mathrm{s}$, the WBGT ranges from a low value calculated with formula (4) where $t_{n w}$ is replaced by $t_{w b}$ to a high value calculated with formula (4) using $t_{n w}$. This range is possible if $T_{a}$ and $\mathrm{T}_{\mathrm{g}}$ are close. According to ISO 11399 [40], the WBGT allows a quick and easy evaluation of thermal conditions. When WBGT thresholds are exceeded, the ISO 11399 [40] standard recommends using $\mathrm{Sw}_{\text {req }}\left(\mathrm{W} / \mathrm{m}^{2}\right)$, the required sweat rate from ISO 7933 [44]. Therefore, $\mathrm{Sw}_{\text {req }}$ is used for a high level of risk. $\mathrm{Sw}_{\text {req }}$ is more precise than WBGT and presents exposure thresholds of less than one hour, which is below the time step of the thermal model used here.

The selection of indices and their thresholds is not imposed; rather, it requires technical and scientific approaches and the designer and building owner bear liabilities. In the paper, the use of standards, especially the first alert level, i.e., the WBGT, provides stakeholders a safe level in the design of buildings.

A practical approach using an example is used to determine the boundary between thermal comfort and heat stress.

\subsection{Example description}

The climate conditions, dwelling characteristics and occupant behaviours that were selected for numerical simulation are given in the following sections.

Without future climate data available for the numerical model (a set of 8 meteorological parameters with an hourly time step), a heatwave episode is chosen according to the HHWWS (\$2.3). The selected period is the first week of July 2015 in the Paris-Orly area in France. Table 1 summarizes the IBM thresholds and daily values. 


\begin{tabular}{ccccccccc}
\hline IBM & Thresholds & Day 1 & Day 2 & Day 3 & Day 4 & Day 5 & Day 6 & Day 7 \\
\hline IBMin $\left({ }^{\circ} \mathrm{C}\right)$ & 21 & 15 & 16 & 16 & 18 & 19 & 20 & 21 \\
IBMax $\left({ }^{\circ} \mathrm{C}\right)$ & 31 & 29 & 28 & 31 & 34 & 35 & 36 & 33 \\
\hline
\end{tabular}

Table 1: IBM thresholds and daily values during the selected heat wave

A three-room middle-floor dwelling without an air-conditioning system is selected. The dwelling has a $68 \mathrm{~m}^{2}$ surface area and a $170-\mathrm{m}^{3}$ volume, with a single-sided ventilation that is mainly oriented to the south (Figure 5).

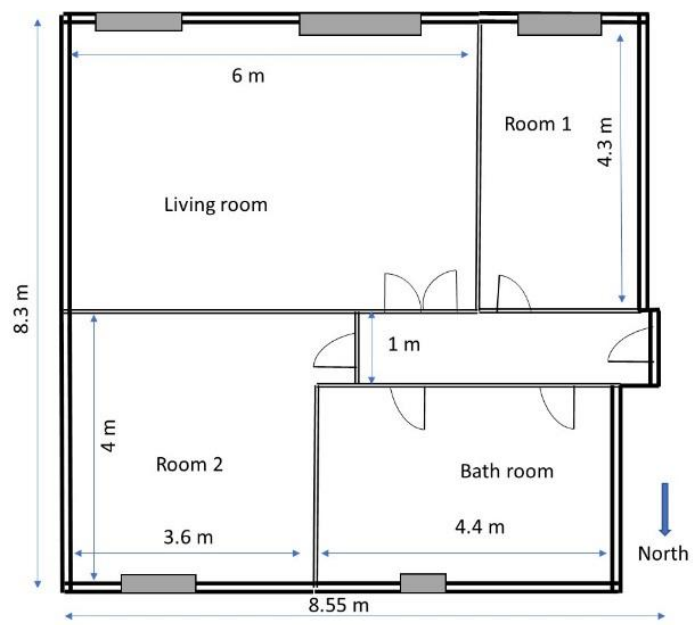

Figure 5: Scheme of the dwelling geometry

The insulation and airtightness levels that were recommended in Effinergie guidebooks [45] are used. A 0.19 $\mathrm{W} /\left(\mathrm{m}^{2} . \mathrm{K}\right) \mathrm{U}$ value is used for the walls, and a 0.3 value is used for the temperature correction coefficient for the buffer zone (i.e., the stairwell). External insulation and the concrete structure lead to heavy inertia. Daily and hourly thermal capacities of each wall are calculated with ISO 13786 [29]. The Th-I French professional rules [46] are used to obtain dwelling thermal capacity $\mathrm{C} \mathrm{kJ} /\left(\mathrm{K} . \mathrm{m}^{2}\right)$, which is given per square meter of the dwelling surface area. The daily $\mathrm{C}$ value is $264 \mathrm{~kJ} /\left(\mathrm{K} \cdot \mathrm{m}^{2}\right)$, and the hourly $\mathrm{C}$ value is $115 \mathrm{~kJ} /\left(\mathrm{K} \cdot \mathrm{m}^{2}\right)$. The window characteristics (Table 2) are selected with the Th-S French professional rules [46]. Diffusing blinds completely cover the windows but allow partial light. This choice is efficient in protecting the indoor environment from heat and is a safe solution in a heat-related health risk approach.

\begin{tabular}{|c|c|c|c|c|}
\hline Area $\left(\mathbf{m}^{2}\right)$ & $\begin{array}{c}\mathbf{U w} \\
\left(\mathbf{W} /\left(\mathbf{m}^{2} \cdot \mathbf{K}\right)\right)\end{array}$ & $\begin{array}{c}\text { Direct solar } \\
\text { transmittance } \\
{[47]}\end{array}$ & $\begin{array}{c}\text { Secondary internal } \\
\text { heat transfer factor } \\
{[47]}\end{array}$ & Description \\
\hline $\begin{array}{l}11 \quad(8.26 \\
\text { south and } \\
2.73 \text { north })\end{array}$ & 1.6 & 0.09 & 0.05 & $\begin{array}{l}\text { 4/16/4 double glazing, low-emissive glass, } \\
\text { argon-filled gap, light-coloured outer solar } \\
\text { protection, solar transmission rate of } 0.2 \text {. }\end{array}$ \\
\hline
\end{tabular}

Table 2: Window characteristics

According to the French regulations [48], the mechanical ventilation system provides air renewal of approximately 0.3 air change per hour $(\mathrm{ACH})$ and runs at all the times. The airtightness of the building envelope leads to an infiltration air flow rate of less than $0.1 \mathrm{ACH}$. The southern windows are open when the outside temperature is 
below the indoor temperature, which is supposed to be an optimal cooling strategy. The northern windows are never open. The air flow rates through the windows are calculated according to the De Gids model [30], with a 1.5 $\mathrm{m}$ height for the opening and 3 opening window areas of $0 \mathrm{~m}^{2}, 1 \mathrm{~m}^{2}$ and $5 \mathrm{~m}^{2}$.

Internal heat loads and humidity production are given according to human activity. Three occupants are supposed to be present in the dwelling throughout the day and awake from 8 AM to $11 \mathrm{PM}$, as in the French thermal regulations [49]. The metabolic data are selected to match the ISO 7730 [19] and ISO 7243 [20] scopes. The activity of each occupant is assumed to be sedentary (1.2 Met, i.e., $126 \mathrm{~W})$. Body water vapour losses are not dependent on the indoor temperature. For each occupant, an $85 \mathrm{~g} / \mathrm{h}$ metabolic vapour production is used, which matches sedentary activity at $28^{\circ} \mathrm{C}$ [50]. At each hourly time step, the appliance loads range from 8 to $12 \mathrm{~W} / \mathrm{m}^{2}$ during the time awake.

The PMV is calculated according to ISO 7730 [19], with 1.2 Met, 0.6 Clo for clothing insulation, and two air velocity $\left(\mathrm{V}_{\mathrm{a}}\right)$ values, $0.1 \mathrm{~m} / \mathrm{s}$ and $0.4 \mathrm{~m} / \mathrm{s}$. These assumptions are also used to select the threshold proposed for the WBGT; ISO 7243 [20] recommends not exceeding a $29^{\circ} \mathrm{C}$ WBGT for unacclimated people.

\section{RESULTS}

Table 3 gives the air change rates and temperatures during the investigated period. The mean, standard deviation (SD), minimum and maximum (min : max) values are given for the three open-window conditions.

\begin{tabular}{|c|c|c|c|c|c|c|}
\hline \multirow{2}{*}{$\begin{array}{l}\text { Open windows } \\
\left(\text { area, } \mathbf{m}^{2}\right)\end{array}$} & \multicolumn{2}{|r|}{$\operatorname{ACH}\left(h^{-1}\right)$} & \multicolumn{2}{|r|}{ Top $\left({ }^{\circ} \mathrm{C}\right)$} & \multicolumn{2}{|r|}{ Toutside $\left({ }^{\circ} \mathbf{C}\right)$} \\
\hline & Mean & SD $(\min : \max )$ & Mean & $\mathrm{SD}(\min : \max )$ & Mean & $\mathrm{SD}(\min : \max )$ \\
\hline No $\left(0 \mathrm{~m}^{2}\right)$ & 0.4 & $0.007(0.38: 0.41)$ & 37.6 & $1.7(34: 40)$ & 26 & $5.3(17: 39)$ \\
\hline Low $\left(1 \mathrm{~m}^{2}\right)$ & 1.4 & $0.3 \quad(0.65: 1.9)$ & 29.5 & $1.9 \quad(25: 33)$ & 26 & $5.3(17: 39)$ \\
\hline $\operatorname{High}\left(5 \mathrm{~m}^{2}\right)$ & 7.6 & $1.6 \quad(3.5: 9.8)$ & 26.6 & $1.9 \quad(23: 30)$ & 26 & $5.3(17: 39)$ \\
\hline
\end{tabular}

Table 3: Temperatures and air change rates during the heatwave

In these simulations, opening windows at the right time is needed to avoid heat stress. Widely opened windows increase the ventilation rate, and the maximum and minimum Top can be lowered by approximately $10^{\circ} \mathrm{C}$. Increasing open window areas from 1 to $5 \mathrm{~m}^{2}$ leads to a $3^{\circ} \mathrm{C}$ decrease in Top. To better understand the interaction between natural ventilation and the indoor environment, the indoor temperature courses are represented in Figure 6. The green circles represent the Top for the high-airing condition, and the blue crosses represent the Top for the low-airing condition. The upper limit of the thermal comfort range, the red line, is calculated for a PPD under $10 \%$ according to ISO 7730 [19], with a $0.4 \mathrm{~m} / \mathrm{s}$ air velocity and assuming a $50 \%$ relative humidity. This threshold is exceeded on the $5^{\text {th }}$ and $6^{\text {th }}$ days even with a high open window area. 


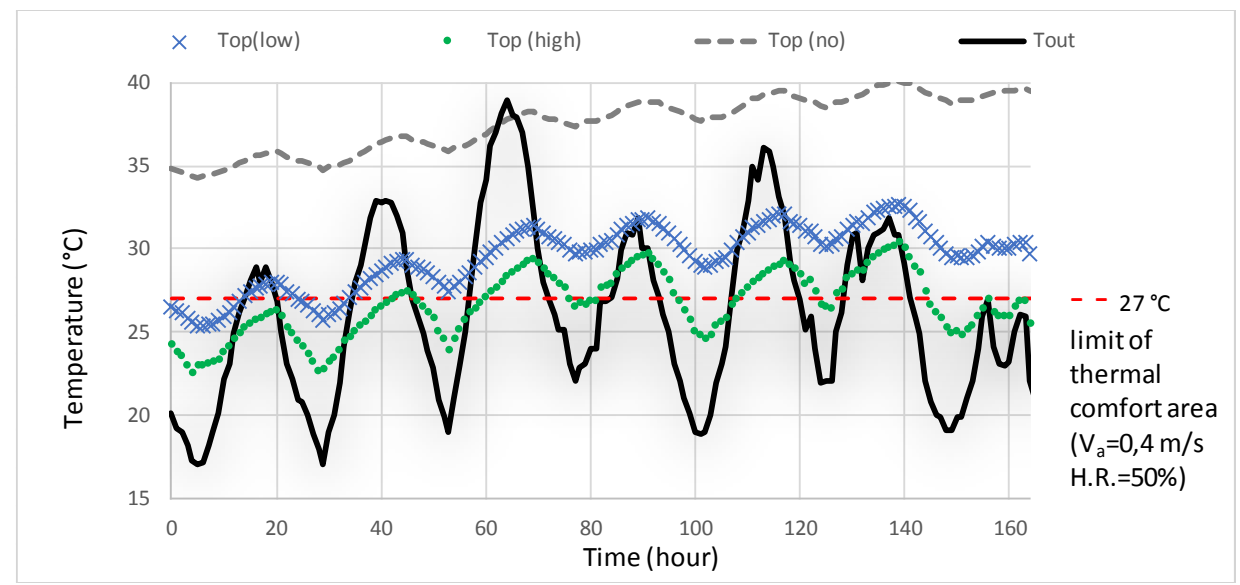

Figure 6: Impact of outside temperature on indoor temperatures during the heatwave.

The high and low ventilation rates lead to similar temperature courses. High ventilation reduces the gap between the indoor and outdoor night temperatures (solid black line). During the final five days of the heatwave, the operative temperature ranges from $25^{\circ} \mathrm{C}$ to $30^{\circ} \mathrm{C}$ when the windows are open wide $\left(5 \mathrm{~m}^{2}\right)$ and from $27^{\circ} \mathrm{C}$ to $33^{\circ} \mathrm{C}$ for a $1 \mathrm{~m}^{2}$ window opening. These values are lower than the outside maximal temperature, which reaches $39^{\circ} \mathrm{C}$. In these examples, natural ventilation is efficient at reducing the temperature. Nevertheless, it is unclear whether the indoor environment is comfortable or if it causes heat stress.

Assumptions related to metabolic activity introduced in $\$ 2.7$ are used to select the threshold proposed for the WBGT, as ISO 7243 [20] recommends not exceeding a $29^{\circ} \mathrm{C}$ WBGT for unacclimated people. Each index is then calculated during the awake period. Table 4 presents the main results relative to thermal comfort and heat stress. Multiple times, $\mathrm{T}_{\mathrm{a}}$ and $\mathrm{T}_{\mathrm{rm}}$ exceed the recommended comfort standard limits. When this situation occurs, the letters [O.R.] (Out of Range) are added after the PPD values in Table 4. For a $0.4 \mathrm{~m} / \mathrm{s}$ air velocity, two WBGT values are given in the table: an overestimation value calculated with $t_{n w}$ from the Malchaire formula [43] and an underestimation value, in italics and heavily lined, calculated by replacing $t_{\mathrm{nw}}$ with the dry bulb temperature $\mathrm{t}_{\mathrm{wb}}$. 


\begin{tabular}{|c|c|c|c|c|c|c|}
\hline $\begin{array}{c}\text { Open } \\
\text { windows } \\
\left(\text { area } \mathbf{m}^{2}\right)\end{array}$ & $\begin{array}{c}\text { Air } \\
\text { velocity } \\
(\mathbf{m} / \mathbf{s})\end{array}$ & $\begin{array}{c}\text { Relative } \\
\text { Humidity }(\%) \\
\text { min : } \max \end{array}$ & Mean & $\begin{array}{c}\text { PPD (\%) } \\
\text { SD (min : max) }\end{array}$ & Mean & $\begin{array}{l}\text { WBGT }\left({ }^{\circ} \mathrm{C}\right) \\
\text { SD }(\min : \max )\end{array}$ \\
\hline \multirow[b]{2}{*}{ No $\left(0 \mathrm{~m}^{2}\right)$} & 0.1 & $32: 45$ & 99.9 & 0.32 (98 [O.R] : $100[$ O.R]) & 29.5 & $0.9(27.4: 30.7)$ \\
\hline & 0.4 & $32: 45$ & 99.9 & $0.25(98[\mathrm{O} . \mathrm{R}]: 100[\mathrm{O} . \mathrm{R}])$ & $\begin{array}{l}29.5 \\
29.2\end{array}$ & $\begin{array}{l}0.9(27.4: 30.7) \\
0.9(27.1: 30.4)\end{array}$ \\
\hline \multirow[b]{2}{*}{ Low $\left(1 \mathrm{~m}^{2}\right)$} & 0.1 & $31: 61$ & 51.5 & $23.7(7: 87$ [O.R]) & 23.5 & $1.5(20.4: 26.4)$ \\
\hline & 0.4 & $31: 61$ & 42.6 & $25.25(5: 86[$ O.R] $)$ & $\begin{array}{l}23.5 \\
23.1\end{array}$ & $\begin{array}{l}1.5(20.4: 26.4) \\
1.6(19.9: 26.2)\end{array}$ \\
\hline \multirow[b]{2}{*}{$\operatorname{High}\left(5 \mathrm{~m}^{2}\right)$} & 0.1 & $39: 69$ & 23.2 & $18 \quad(5: 67$ [O.R] $)$ & 22.2 & $2(18.7: 25.5)$ \\
\hline & 0.4 & $39: 69$ & 17.6 & 14.5 (5 : 59 [O.R]) & $\begin{array}{l}22.2 \\
21.9\end{array}$ & $\begin{array}{l}2(18.7: 25.5) \\
2.1(18.1: 25.2)\end{array}$ \\
\hline
\end{tabular}

Table 4: Indoor thermal comfort and heat stress indices during the heatwave

When windows are closed, the indoor environment conditions greatly deteriorate, and the WBGT awareness limits are exceeded. With wide-open windows $\left(5 \mathrm{~m}^{2}\right.$, high area), the indoor conditions are generally maintained at a moderate thermal environment within the scope of the standard. The calculated WBGT is lower than the proposed standard limits. In the two contrasting situations, the ergonomic standard indices are reliable. For a $1 \mathrm{~m}^{2}$ window opening, the results are more difficult to analyse than for a wide opening. The mean PPD value for a $0.4 \mathrm{~m} / \mathrm{s}$ air velocity is close to the recommended ISO 7730 limits [19] but does not reach the thermal stress threshold.

To study the boundaries between comfort and heat stress, the PPD is plotted versus the WBGT for the example with a low opening area (Figure 7). Both indices are calculated during the heatwave.

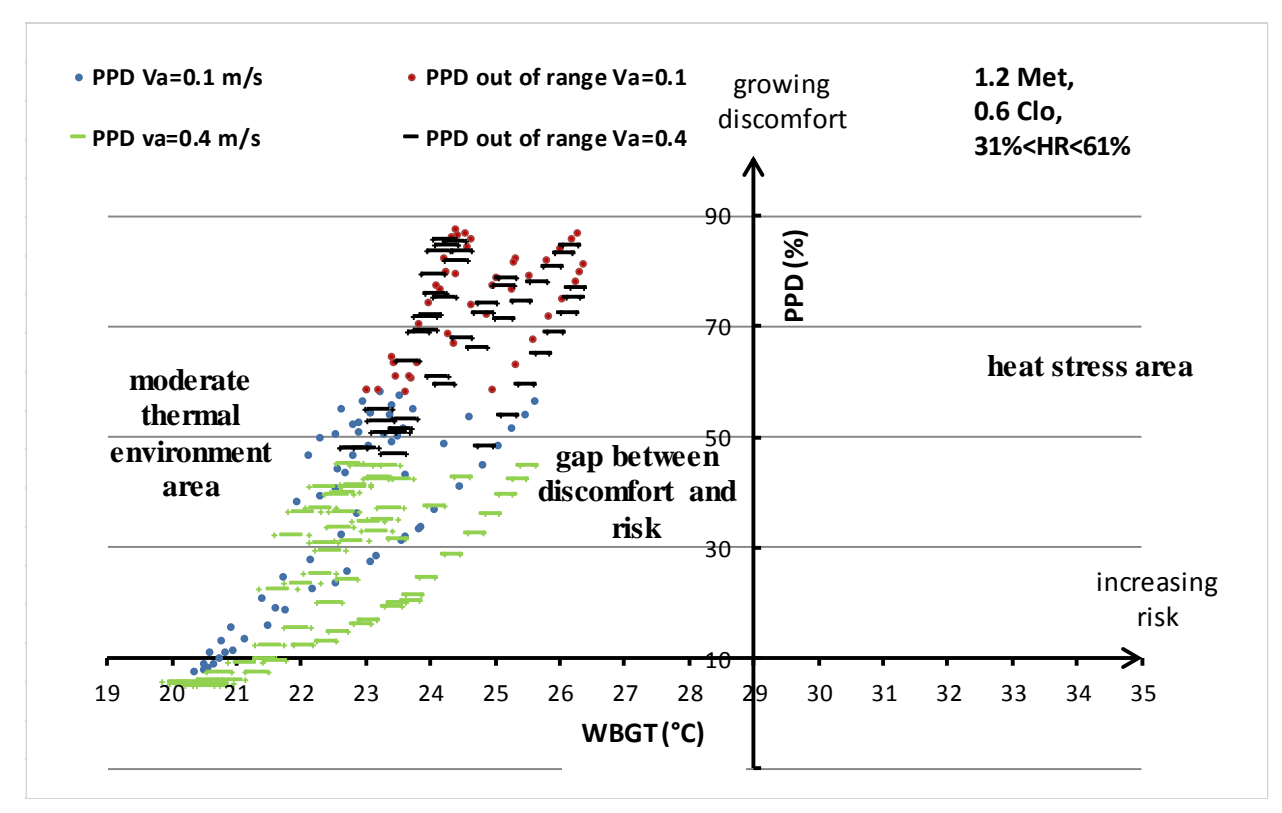

Figure 7: PPD versus WBGT for a building with a $1 \mathrm{~m}^{2}$ window opening during the heatwave 
Blue and red circles indicate the PPD calculated with a $0.1 \mathrm{~m} / \mathrm{s}$ air velocity, and green and black dashes indicate the PPD calculated with a $0.4 \mathrm{~m} / \mathrm{s}$ air velocity for a range of WBGT values. Red circles and black dashes indicate that the PPD is calculated out of the standard recommended range. The PPD values calculated with a $0.1 \mathrm{~m} / \mathrm{s}$ air velocity (blue circles) are mainly above the x-axis, which is at 10\% dissatisfied. Thus, according to ISO 7730 [19], the indoor thermal environment is often uncomfortable. Due to a $0.4 \mathrm{~m} / \mathrm{s}$ air velocity, thermal comfort is improved with an increased number of hours during which the PPD is below $10 \%$ as shown by the green dashes.

For PPD values above $60 \%$ for a $0.15 \mathrm{~m} / \mathrm{s} \mathrm{V}_{\mathrm{a}}$ and $45 \%$ for a $0.4 \mathrm{~m} / \mathrm{s} \mathrm{V}_{\mathrm{a}}$, the moderate thermal environment range is exceeded. Numerous red circles and black dashes indicate that the indoor environment is often over the moderate thermal environment limits. However, the red circles and black dashes are also below the heat stress limits according to the $29^{\circ} \mathrm{C}$ WBGT threshold, and thus, according to ISO 7243 , reducing the thermal stress is not required, and a more detailed analysis, i.e., calculation of the required sweat rate according to ISO 7933 [44], is not necessary. However, for a $33^{\circ} \mathrm{C}$ Top (Table 3), it is optimistic to consider that the situation provides healthy conditions. Indeed, when $32^{\circ} \mathrm{C}$ is exceeded, the ISO 15265 [39] observation scale recommends preventive steps. Moreover, the different ways in which indoor air humidity affects WBGT and PPD make it difficult to distinguish between the moderate thermal range and the heat stress threshold. In our example, the indoor humidity is in a narrow range most of the time, with a $44 \%$ mean $\mathrm{RH}$ value and $7.5 \% \mathrm{SD}$, although it occasionally ranges from 30 to $60 \%$ (Table 4). Thus, for a WBGT between $23^{\circ} \mathrm{C}$ and $26^{\circ} \mathrm{C}$, the indoor environment can be in the moderate thermal range or somewhat outside this range without entering the heat stress range. Thus, in this situation, the gap between the two standard indices is too large to determine whether the indoor environment is safe.

\section{DISCUSSION}

PPD and WBGT are attractive indices because they can be obtained from physical environmental parameters and are consistent with the building thermal model. These indices and thresholds from the literature help to build the first step towards a continuum between thermal comfort and heat stress.

According to the thresholds, the method is limited to healthy people without special requirements. Although the scope is limited to an apparently homogeneous population, the observed gap indicates that a sharp border between thermal comfort and heat stress does not appear.

Two physical parameters, namely, $\mathrm{V}_{\mathrm{a}}$ and $\mathrm{RH}$, are striking. The weight assigned to humidity in the WBGT seems too strong for the moderate thermal environment limits. Moreover, the WBGT thresholds appear to be too high for low air velocities. Thus, a return to the initial experimental conditions used to build WBGT and its thresholds is necessary. G.M. Budd [51] explains that the impacts of evaporation increase with temperature. However, the $t_{n w}$ weight factor is set to 0.7 in the WBGT. In the moderate thermal environment (44\% mean RH and $7.5 \%$ SD) 
studied, the dry temperature weight factor (set at 0.3 ) should increase and lead to an increase in the WBGT in the tested example with a $1 \mathrm{~m}^{2}$ window opening. The WBGT does not indicate air velocity reduction effects. Because the WBGT was developed for an outside environment, the $V_{a}$ values that led to the identification of the WBGT safety thresholds were probably higher than those in our study. However, heat resilience is strongly reduced at low $\mathrm{V}_{\mathrm{a}}$ values because of the reduction of air potential evaporation [51]. For an indoor environment without wind, the existing WBGT limits might be reduced. Meyer, Rapp and Vogt [52] recommend avoiding the exceedance of a $25^{\circ} \mathrm{C}$ value for the WBGT, which would lead to an overlap of the moderate thermal environment and heat stress ranges in the calculated example. A $25^{\circ} \mathrm{C}$ WBGT leads to a PPD above $48 \%$ and $36 \%$ for a $0.15 \mathrm{~m} / \mathrm{s}$ and a $0.4 \mathrm{~m} / \mathrm{s}$ air velocity, respectively. The overlap occurs far from the 15\% PPD, the thermal comfort threshold recommended by the annex A of ISO 7730 [19].

WBGT was invented in the 1950s to avoid heat illness in the US army [51] and thus is strongly dependent on this type of population. The PMV is also focused on healthy people, whereas the WBGT was invented for a population that is likely highly resistant to heat stress. The difference in thermal stress sensitivity of these populations also explain the observed gap.

Many of the detailed relationships between indoor thermal climate and human health are poorly understood in epidemiological terms. The physiological responses to a given thermal stress are variable; thus, it is difficult to accurately predict an individual response. Indeed, according to Candas [53], two kinds of adaptation to heat exist. The first adaptation is a behavioural response to reduce heat stress, and the second adaptation is a physiological response that limits the consequences of heat strain under heat stress. The physiological response depends on the sensitivity of an individual and their level of acclimatisation. However, according to Hanna [54], acclimatisation occurs after long-term heat exposure mixed with gradual physical activity. Thus, acclimatisation depends on the physiological state of an individual and their training. Thus, a comfort to health risk continuum should be built for each type of person according to their physiology and training. The distribution of people through three levels of acclimatisation, as proposed by Hanna [54], could be used to establish a link between the thermal comfort range and heat stress threshold for each of those acclimatisation levels.

\section{CONCLUSIONS AND PERSPECTIVES}

The objective of this study was to determine whether natural ventilation could be a sustainable solution to protect occupants from heat-related health risks during heatwaves in the context of adaptation to climate change. The efficiency of this passive system to refresh dwellings depends strongly on the local climate, building characteristics and occupant behaviour. Because of their high variability, a generic answer regarding the ability of the system to avoid heat related health risks cannot be given. A method using standards dedicated to professional building design 
was considered relevant and was developed, and it only pertains to healthy people at sedentary activity levels and without any special requirements.

This method was tested using an example to determine whether it is functional. Thus, the cooling potential of the ventilative cooling calculated for this example cannot be extended to other situations. Nevertheless, these preliminary results are promising because the indoor environment in the tested example is safe if the windows are widely opened at the relevant times.

However, some tools are missing or need to be improved to achieve a sufficiently effective method before use by professionals. A method to select future climate data with an appropriate confidence range and occurrence probability must be developed. At the design stage, the thermal and air flow models should be selected according the balance between their accuracy and the availability of their input data. A more objective approach than this method would be to provide a confidence range for each calculated index. A sensitivity study, which was limited here to windows opening conditions, could also be performed. In this paper, no specific tool is recommended. Our choice was driven by the wish to be accessible and recognizable to building designers and provide results in accordance with ASHRAE 140 standard [26].

At the intersection of PMV/PPD comfort and WBGT risk indicators, the design of an effective solution can theoretically be balanced. However, a gap is observed between the legitimate domain of ISO 7730 [19], which is used for PPD calculation, and the WBGT thresholds that were proposed in ISO 7243 [20]. This gap can be explained by the discrepancies between the standard experimental conditions used to quantify the indices. Thus, further investigation is required to identify the threshold values between thermal comfort and heat-related health risks. Investigations could be enlarged to more vulnerable people and those with different metabolisms. The acclimatisation level of people has to be known to enhance the continuum. The distribution of the population proposed by Hanna [54] could be used.

Moreover, two key issues are suggested because of their strong impact on the potential of ventilation to protect people during heatwaves: the selection of both the occupant scenarios and the hot periods.

In this study, the potential to cool the building was assessed using the optimal scenario. The choice of scenarios should be discussed with stakeholders to consider realistic occupant behaviours to the extent possible. Building designers and owners should be involved in this choice because they provide advice to occupants to adapt their behaviours during heatwaves.

In this study, climate data were selected at the heatwave alert level according to the HHWWS. Midler climate conditions should be tested to determine the ability of naturally ventilated dwellings to protect people from thermal 
stress. Indeed, according to the dynamic thermal response of the dwelling, the indoor environmental conditions could be unsafe under mild weather conditions, typically at a HHWWS warning level or seasonal vigilance.

\section{ACKNOWLEDGEMENTS}

This research was funded by the CSTB Research Program on Risk Control. The authors thank S. Lacour (IRSTEA) for her help with computing the wet-bulb temperature, P. Delpech (CSTB) for his support, C. Cochet (CSTB) for his review, A. Machard (LaSIE) for providing figures of future climate in Paris, and K. Begredj (CSTB) for his help with the COMETh model.

\section{REFERENCES}

[1] The Lancet Commission, "health and climate change : policy responses to protect public health," The Lancet, vol $386 n^{\circ} 10006$, pp. 1861-1914, 2015.

[2] C. Koppe, S. Kovats, G. Jendritzky and B. Menne, Heat-waves: risk and response, World health Organisation. Health and Global Environmental Change Series, n².124p, 2004.

[3] S. Kovats and S. Hajat, "Heat stress and Public Health: a critical review," Annu. Rev. Public health, (29), pp. 41-55, 2008.

[4] D. Hémon and E. Jougla, "La canicule du mois d'août 2003 en France,” Rev. Epidémiol. Santé Publique, 52(1), pp. 3-5, 2004.

[5] K. Laaidi, A. Ung, V. Wagner, P. Beaudeau and M. Pascal, The French Heat and Health Watch Warning System: principles, fundamentals and assessment, Saint-Maurice: InVS, 2013, p. 17 pages.

[6] A. Fouillet, G. Rey, V. Wagner and e. al., "has the impact of heatwaves on mortality changed in France since the European heat wave of summer 2003? A Study of the 2006 heat wave," International Journal of Epidemiology, pp. 37 : 309-317, 2008.

[7] K. Laaidi, A. Ung, M. Pascal and P. Beaudeau, "Vulnérabilité à la chaleur: actualisation des connaissances sur les facteurs de risque," Bull Epidémiol Hebd. (5), pp. 76-82, 2015.

[8] J. Ribéron, S. Vandentorren, P. Bretin, A. Zeghnoun, G. Salines, C. Cochet, C. Thibault, M. Hénin M and M. Ledrans, "Building and Urban factors in Heat-Related Deaths during the 2003 Heatwave in france," in Healthy buildings conference, Lisboa, Portugal, 2006. 
[9] S. Vandetorren, P. Bretin, A. Zeghnoun, L. Mandereau-Bruno, A. Croisier, C. Cochet, J. Ribéron, I. Siberan, B. Declercq and M. Ledrans, “August 2003 Heatwave in France: Risk factors for Death of Elderly Oeople living at Home,” Eur. J. Public Health(16), pp. 583-591, 2006.

[10] L. Grignon-Massé, P. Rivière and J. Adnot, "Strategies for reducing the environmental impacts of room air conditioners," vol. 39, 2011.

[11] F.-X. Dussud, D. Lepoittevin and N. Riedinger, "Les ménages et la consommation d'énergie," Service de l'observation et des statistiques (SOeS)., 2017.

[12] M. Santamouris, “Cooling the buildings-past, present and future," Energy and Buildings 128, pp. 617-638, 2016.

[13] Ademe et vous, “À Pantin, une école fraîchement réglementaire,” Pantin (Paris suburb), 2014.

[14] CEN Guide 32, "Guide for addressing climate change adaptation in standards," CEN 42p, 2016.

[15] C. Folland, T. Karl, J. Christy, R. Clarke, G. Gruza and J. Jouzel , “Observed climate variability and change. In: climate change 2001: the scientific basis. Contributionof WG. I to the third assessment report of IPCC [Houghton, J.T. et al. (eds)],” Cambridge University Press, 881pp, 2001.

[16] Drias, données Météo-France, CERFACS and IPSL, "Drias Futures of Climate,” Avril 2018. [Online]. Available: http://www.drias-climat.fr/.

[17] T. Stocker, D. Qin, G.-K. Plattner, L. Alexander and et al., “Technical Summary. In: Climate Change 2013: The Physical Science Basis. Contribution of Working Group I to the Fifth Assessment Report of the Intergovernmental Panel on Climate Change,” Cambridge University Press, Cambridge, United Kingdom and New York, NY, USA., 2013.

[18] ISO 15927-2, NF EN ISO Hygrothermal performance of buildings calculation and presentation of climatic data. Part 2: Hourly data for design cooling load, AFNOR 2009, 2009.

[19] ISO 7730, NF EN ISO, standard analytical determination and interpretation of thermal comfort using calculation of the PMV and PPD indices and local thermal comfort criteria, AFNOR, 2006, 2006.

[20] ISO 7243, NF EN ISO Hot environments-estimation of the heat stress on working man, based on the WBGT-index (wet bulb globe temperature), AFNOR 1994, 1994.

[21] ISO 13790, "NF EN ISO Energy performance of buildings- Calculation of energy use for space heating and cooling," AFNOR, 2013. 
[22] EN 15242, NF EN Ventilation for buildings. Calculation methods for the determination of air flow rates in buildings including infiltration., AFNOR, 2007, 2007.

[23] M. Pascal, K. Laaidi and M. Ledrans, “france's heat and health watch warning system,” int. J Biometeorol 50, pp. 144-153, 2006.

[24] J.-B. Videau, J.-M. Alessandrini, B. Haas, C. Pelé, J.-R. Millet, P. Jallet, L. Reynier and E. Fleury, “An introduction to the development of the French energy regulation indicators and their calculation methods," in CLIMA, Prague CZ, 2013.

[25] D. Da Silva, J.-M. Alessandrini, J.-B. Videau, C. Pelé and J.-R. Millet, "Evaluation et perspectives du modèle thermique de COMETh, le coeur de calcul de la RT des bâtiments neufs.," in IBPSA France, Marne-la-Vallée, 2016a.

[26] ASHRAE 140, Method of test for the evaluation of building energy analysis computer programs, ANSI/ASHRAE,Atlanta,92p, 2001.

[27] D. Da Silva, J.-M. Alessandrini, J.-B. Videau and C. Pelé, International standards and thermal dynamic model for building regulation: validity and limits, Séoul: IAQVEC , p. 8,, $2016 \mathrm{~b}$.

[28] G. Walton, “A new algortihm for radiant interchange in room loads calculations,” ASHRAE Trans. (86), pp. 190-208, 1980.

[29] ISO 13786, "NF EN ISO Thermal performance of building components Dynamic thermal charateristics Calculation methods," AFNOR, 2008.

[30] W. De Gids and H. Phaff, "Ventilation Rate and Energy Consumption due to Open Windows.," Air Infiltration review, vol. 1, no. 4, pp. 4-5, 1982.

[31] IEA, “Air flow through openings in buildings," International Energy Agency; IEA/ECB-Annex 20 : Air Flow Patterns Within Buildings. Subtask-2. Technical report, Jacobus van der Maas, EPFL, Lausanne, Switzerland, 1992.

[32] T. Larsen, P. Heiselberg and T. Sawatchi, "Analysis and design of single-sided natural ventilation," in Proceedings of ISHVAC, The 4th International Symposium on Heating, Ventilation and Air-Conditioning, Beijing, China Tsingua University October 9-11 2003, 2003.

[33] M. Goromosov, The physiological basis of health standards for dwelling. 100 pages, Geneva: World Health Organization, 1968. 
[34] WHO, Indoor Environment: Health aspects of air quality, thermal environment, light and noise. WHO/EHE/RUD/90.2., 127 pages, Geneva: World Health Organization, 1990.

[35] WHO, Climate and Human Health. World Climate programme applications, Geneva: World Health Organization 18p, 1987.

[36] NOAA., Heat Index Chart. National Oceanic and Atmospheric Administration., Silver Spring, USA: http://www.nws.noaa.gov/os/heat/heat_index.shtml, 1985.

[37] Fanger, P.O., Thermal comfort, Malabar Fl: Robert E. Krieger, 1982.

[38] EN 15251, NF EN Indoor environmental input parameters for design and assessment of energy performance of building adressing indoor air quality, thermal environment, lighting and acoustic, Afnor $2007,2007$.

[39] ISO 15265, "NF EN ISO risk assessment strategy for the prevention of stress or discomfort in thermal working conditions," AFNOR, 2004.

[40] ISO 11399, NF EN ISO Principles and application of relevant International Standards, AFNOR 2001, 2001.

[41] P. Fanger, A. Melikov, H. Hanzawa and J. Ring, "Air turbulence and sensation of draught,” Energy and Buildings, pp. 12 : 21-39., 1988.

[42] ISO 7726, NF EN ISO Ergonomics of the thermal environment:Instruments for measuring physical, AFNOR, 2002.

[43] J.-B. Malchaire, "Evaluation of natural wet bulb and wet globe thermometers," Ann. Occup. Hyg.(19), pp. 251-258, 1976.

[44] ISO 7933, AFNOR 2005, 2005.

[45] Effinergie, Le guide technique "Réussir un projet Effinergie, des clés pour des logements neufs confortables et économes en énergie" 34p, 2008.

[46] CSTB, "Règles de calcul Th-I and Th-S guide réglementaire-R.T. 2012,” CSTB, 2012.

[47] ISO 52022-3, Energy performance of buildings - Thermal, solar and daylight properties of building components and elements - Part 3 :Detailed calculation method of the solar and daylight characteristics for solar protection devices combined with glazing, AFNOR, 2017.

[48] Arrêté , Arrêté du 24 mars 1982 : Disposition relative à l'aération des logements., 1982. 
[49] J.O., Arrêté du 30 avril 2013 portant approbation de la méthode de calcul Th-BCE, Journal Officiel de la République Française, 2013.

[50] le Recknagel, Manuel pratique du génie climatique, tome 1 Données fondamentales, Pyc Ed, 1995.

[51] G. M. Budd, Wet-bulb globe temperature (WBGT)-its history and its limitations, 11, 20-32, Journal of Science and Medicine in Sport, 11, 20-32, 2008.

[52] J. Meyer, R. Rapp and J. Vogt, “Campagne de comparaison de la validité respective des principaux indices de contraintes thermiques. [Rapport de recherche] Notes scientifiques et techniques de l'INRS NS 156, Institut National de Recherche et de Sécurité,” Notes scientifiques et techniques de l'INRS NS 156, Institut National de Recherche et de Sécurité 88 p, 1997.

[53] V. Candas, "L'homme dans son environnement climatique : facteurs d'influence, thermorégulation, sensibilité et confort thermiques.," in Colloque « Habitat, Confort et Energie »., 2003.

[54] E. G. Hanna and P. W. Tait, "Limitations to Thermoregulation and Acclimatization Challenge," International Journal of Environmental Research and Public Health, no. 12, pp. 8034-8074, 2015. 